\title{
Modeling the Process of Financing Small Organizations
}

\author{
Natalia Morozko*, Nina Morozko and Valentina Didenko
}

Finance University under the Government of the Russian Federation, 49, Leningradsky Avenue, Moscow, 125993, Russia

\begin{abstract}
Most small business organizations are constantly lacking financial resources. This situation is associated with a small amount of own funds and the difficulty of raising borrowed funds. In the prevailing conditions, the need for wellfounded financing management, this ensures the stable financial condition of a small organization, increases. Modeling the process of financing an organization allows you to consider different financing options, to influence the most significant factors in a particular situation. It is proposed to use the cognitive approach for dynamic management of the financing process and the choice of a rational variant based on the logit model. Determination of the degree of influence of various factors is proposed to be determined using correlation-regression modeling. With the help of the proposed modeling of the financing process of a small organization, it is possible to forecast positive changes in financial performance.
\end{abstract}

Keywords: Management, small business, financing, is modeling.

\section{INTRODUCTION}

Small business organizations are constantly experiencing a shortage of financial resources in the process of their production and economic activities. This situation is due to the fact that own funds in such organizations are not enough, attracting additional resources is difficult, which is caused by the lack of a credit history, lack of collateral, unstable financial condition. There are no ready-made recipes for optimizing sources of financing; therefore small organizations have to apply modern methods of managing financial resources to ensure competitive advantages in the market. Modeling is a popular tool for surveying an unstable and weakly structured environment, to which a small business belongs. Organizations set different goals in attracting financial resources and the direction of their use. The analysis of developments on the justification of financing the activities of small organizations showed that at the present stage such problems are not fully revealed.

The influence of socio-economic factors on the success of small businesses on the basis of regression analysis of results is considered in the article (M. A. Saleem, D.I. Khan, 2012). In conducting banking operations in financing small business, the authors (A. Bellucci, A. Borisov, A. Zazzaro, 2016) use the leastsquares (OLS) model and the Probit model. The study of new forms of financing in the form of Venture Capital, Corporate Venture Capital, Angel Investment, Crowdfunding, and Accelerators was carried out by the

*Address correspondence to this author at the Finance University under the Government of the Russian Federation, 49, Leningradsky avenue, Moscow, 125993, Russia; Tel +79169281200; E-mail: natmorozko@mail.ru

JEL Classification: G32, L26, O21. authors in an article (W. Drover, L. Busenitz, S. Matusik, D. Townsend, A. Anglin, G. Dushnitsky, 2017). In work (S. M. Miller, A. Hoffer, and D. Wille, 2016) conditions and methods of regulation of financing of small business in the USA are investigated. The authors also note alternative sources of financing for small businesses. Authors (Susan Turner, Al Endres, 2017) use system theory, chaos theory, complexity theory, and networking, business planning, and marketing when studying the sources of financing for small business organizations. In work (D. Amel, T. Mach, 2017) it is noted that crediting small businesses in the US using the Small Business Lending Fund (SBLF) according to regression estimates shows an increase in the amount of issued funds by 10 percent. A number of authors (JH Block, MG Colombo, DJ Cumming, S.Vismara, 2018) note that "New players in entrepreneurial finance are emerging and compare them in four aspects: debt or capital, the purpose of investment, the investment approach and the purpose of investment ". Economists (T. Lambert, A.Ralcheva, P.Roosenboom, 2018) consider financing in the form of crowdfunding vs. crowinvesting with Start-Up Financing. In the monograph (J. Wallmeroth, P. Wirtz, A. Groh, 2018) the authors define the linkage of venture capital, angels and crowdfunding in the financing of entrepreneurial enterprises (of Entrepreneurial Ventures). In work (A. Ferrando, E. Mavrakis, A. Ferrando, 2016) the features of financing SMEs in crisis conditions are investigated, it is noted that many firms use commercial credit and leasing as an alternative to bank loans. Forms of financing in the form of: corporate venture capital, angel investments, crowdfunding, accelerators, equity financing are analyzed. 
When conducting a study of the process of financing the activities of companies, it is necessary to take into account the specifics conditioned by the size of the company. A significant part of small business organizations as sources of funding use mainly their own funds - 55-65\%, 25-30\% - borrowed and 5-10\% attracted.

The financial flows of small businesses are affected by various factors: the type of economic activity of the organization; features of the used assets; cost of borrowed capital; profitability of used assets; solvency of counterparties; settlement system and others.

\section{METHODS}

Justification of the choice of sources of financing must be made taking into account the planned structure of capital within the available sources of financing. At the same time, different scenarios of financing possibilities and directions of change are considered. The validity of management decisions in rapidly changing conditions increases with the use of cognitive models. With the application of the cognitive approach, the terms for the development of the organization's development strategy are reduced, and the validity is increased taking into account the influence of external and internal factors. Cognitive structuring allows identifying target and problematic issues in the organization's activities, monitoring the most significant factors, establishing causal relationships between these factors. Cognitive analysis is conducted taking into account the stipulated tasks in several stages.

The main stages of cognitive analysis are:
1. Substantiation of the purpose and objectives of the research.

2. Collection and analysis of statistical information on the object of management, taking into account external influences.

3. Determination of significant factors affecting the change in conditions.

4. Construction of a cognitive map that allows you to establish the cause-effect relationship between the factors.

5. Determination of the degree of mutual influence of factors on the basis of a mathematical model.

7. Identify the likely options for the development of conditions on the basis of the cognitive model, determine the directions of development in order to achieve the set goals.

The first step is the definition of goals and objectives. The purpose of this study is to identify the sources of financing for small businesses based on the modeling of different scenarios. The objectives of the study are: to identify factors that affect rational functioning, the definition of cause and effect relationships, the construction of a functional graph, the definition of a set of managing factors of small company financing.

The selection of the main factors is based on SWOT analysis (Table 1).

Based on the analysis of various possible combinations of strengths and weaknesses with threats and opportunities (SWOT analysis), the problem field of

Table 1: Matrix of SWOT-Analysis of the Activities of a Small Business Organization

\begin{tabular}{|c|c|c|}
\hline \multirow{6}{*}{$\begin{array}{l}\text { Endogenous } \\
\text { factors }\end{array}$} & S - strengths & W - weaknesses \\
\hline & Small initial capital & Lack of financial resources \\
\hline & Significant turnover of funds & A small level of property status \\
\hline & Timely adaptation to change & Lack of funding sources \\
\hline & The owner and manager are represented by one person & The unstable structure of capital \\
\hline & Simplified organizational structure & Inadequate supply of own circulating assets \\
\hline \multirow[t]{5}{*}{ Exogenous factors } & O - opportunities & $\mathrm{T}-$ threats \\
\hline & Increase to the level of large business & The economic situation in the country \\
\hline & Creative self-realization & A large level of competition \\
\hline & Stable position in the local market & Limited demand for products \\
\hline & Probability of getting state support & Significant tax burden \\
\hline
\end{tabular}


the small organizations being researched is formed: a lack of financial resources, a low level of financial stability, insufficient provision of own working capital, significant tax burden, conditions for obtaining state support.

In an open market, business entities have the opportunity to use a wide variety of sources, forms and methods of financing. In this case, it is necessary to take into account the advantages and imperfections of individual sources of financing, compliance with the subject's objectives, minimizing the cost of the resources involved.

\section{Data}

Research of various factors is made on the basis of collection, systematization, analysis of existing statistical information on the indicators of small business organizations of the Russian Federation. At the present stage, the share of small business in the country's GDP is about $18-20 \%$, which is much lower than in developed countries and indicates a significant growth potential. Small business in the Russian Federation is governed by Federal Law No.209-FZ of July 24, 2007 "On the Development of Small and Medium-Sized Enterprises" and Government Resolution No.265 of 04.04.2016. According to these legislative documents, small business organizations include business associations, partnerships, production and consumer associations, farms, as well as individual entrepreneurs with a staff of 16 to 100 people. For small business organizations, the annual income received from entrepreneurial activity cannot exceed 800 MM rub.

Factors-factors in this study are taken on the basis of the data of the System of Professional Analysis of the Market and Companies (SPARC) for small organizations operating in Russia for 2017years (Appendix 1). An array of primary data for the selected list of organizations is based on financial statements for the period under review. To obtain more relevant data, the analysis uses the principles of clustering. In cluster analysis across the entire array, the organizations that did not fall into the mass group were screened out.

Independent factors are chosen taking into account certain requirements:

1. Quantitative determination of independent variables is necessary.
2. The total number of selected factors cannot be large, which greatly complicates the developed model.

3. Independent variables cannot be related by a functional dependence, since they will repeat the evaluation of the event being studied.

\section{Model}

The study and characterization of factors and indicators of the capital structure of the presented set of small organizations were carried out using the method of correlation-regression analysis. The definition of dependent and independent variables within the framework of this method on the sample of small business subjects made it possible to identify the determinants that affect the formation of the capital structure of economic entities. The degree of influence of individual factors on the level of performance of small organizations is determined on the basis of the developed model:

$\mathrm{ROC}=0,32+0.09 \mathrm{CR}-0.21 \mathrm{FL}+0,09 \mathrm{ETAR}+$ 0.04RTR -0.007PTR -0, $15 \mathrm{~T}+1.82 \mathrm{RSS}$

ROC - return on equity;

CR - solvency of the organization;

$\mathrm{FL}$ - the ratio of borrowed funds and own funds;

ETAR - financial stability;

RTR - turnover of accounts receivable;

PTR - turnover of accounts payable;

$\mathrm{T}$ - tax burden;

RSS - the level of state support for small organizations.

The selection of the indicators of organizations was made according to the financial statements of small organizations of the Moscow region as the most representative in the population under consideration. Preliminary analysis of the obtained values allowed ensuring the reliability of the included data, sharply deviating indicators were excluded from the considered population.

When forming a multifactorial correlation model, significant factors were selected that have the most significant effect on the result indicator, since it is practically impossible to cover all the conditions and 
circumstances. The comparability of the indicators was checked for a number of indicators: all indicators have the same units of measure; indicators are commensurable - all indicators are relative values; the indices are homogeneous with respect to the distribution about the mean level. The variation does not exceed $10 \%$, which is confirmed by the homogeneity of the information and the insignificant variability of the considered vibrational series.

To measure the tightness of the connection between the factor and performance indicators, the multiple correlation coefficient $R$ is calculated. When the $R$ coefficient is close to 1.0, a close relationship is noted, a significant deviation indicates a lack of connection. In the proposed model, the value of the multiple correlation coefficients is $R=0.87$, that is, the relationship is significant. The close connection also confirms the determination index is equal to -0.84 .

The proposed model allows us to describe the process of mutual influence of factors of the internal and external environment on the effectiveness of the use of aggregate capital, take into account changes (variations) in the parameters of this environment. Interpretation of the proposed model allows us to conclude that the provision of financial resources for small businesses depends on a certain set of complex parameters. Each of the parameters included in the model characterizes the interactions of various factors that determine the intensity of the organization's financial flows. A certain guideline when developing standards for the coefficients included in the integral model are the following assumptions: to adjust, where possible, standards based on the Russian specifics of the functioning of small organizations, the business activity of this type of organization; apply the resulting average values for the group of values of the coefficients.

The proposed system of indicators is based on the public reporting data of organizations. This condition makes the appraisal affordable, which allows you to monitor changes in the financial state of the organization by all participants in the economic process. It also makes it possible to assess the effectiveness and objectivity of the proposed integrated assessment methodology.

Determining the relationship between factors by considering the cause-effect chains is based on the graph model (Figure 1).

The level of influence of each factor on the score in the developed model is both positive and negative. In the above, it can be seen that, other things being equal, the profitability of capital increases with the increase in ETAR - financial stability (0.09); increase in RTR - receivables turnover $(0,04)$ and increase in the RSS - share of state support; At the same time, the profitability of capital increases with a decrease in $\mathrm{FL}$ the share of borrowed funds $(0.21)$, with a decrease in $\mathrm{T}$ - the tax burden $(0.15)$.

The management of the financing process allows influencing the cash flows of a small organization.

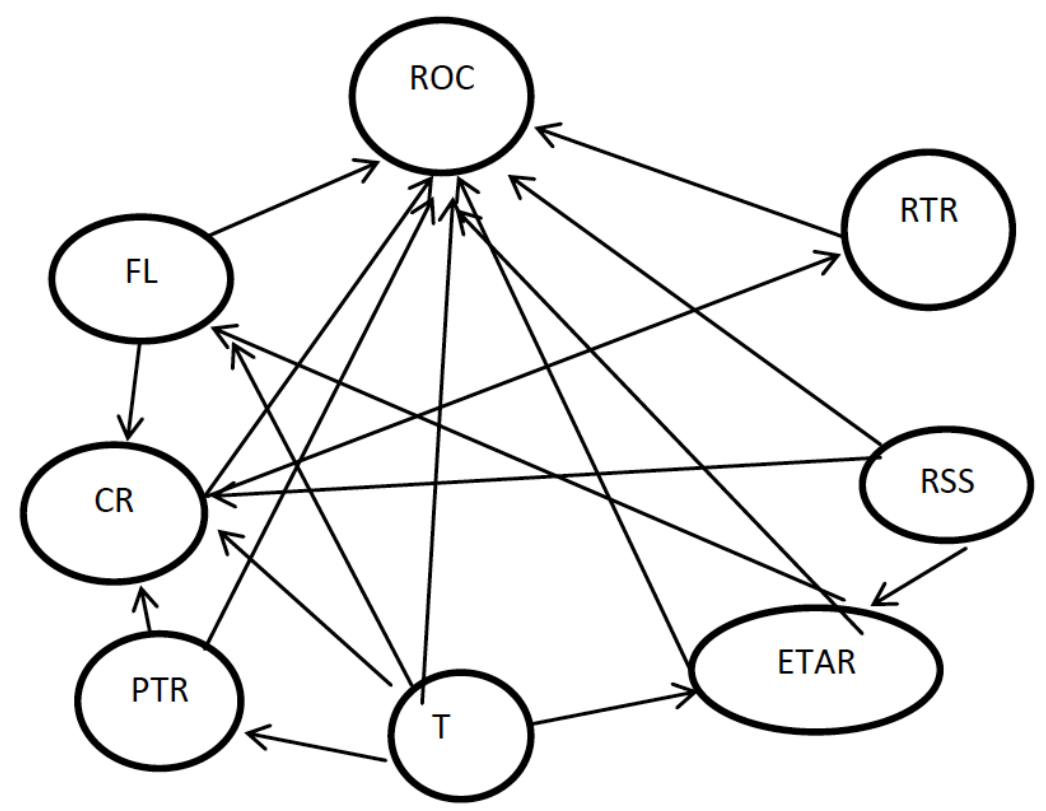

Figure 1: Functional graph for determining the relationships in the financing process. 
These flows are formed under the influence of external and internal influences. External influences include: the taxation system; the level of state support; formed agreements with suppliers and buyers of goods and services; availability of borrowed funds. Internal impacts include those developed by a small organization: the organization's depreciation policy; accounting policy, investment policy and others.

Managing the flow of cash inflows and outflows is very important for assessing the performance of a small organization. The result of the organization's activities is not current cash inflows and outflows, but net cash flow, which affects the increase in the value of the business.

Net cash flow (NCF) in general terms is calculated as follows:

$N C F=I N C F-O U T C F$

Where: INCF - cash inflow;

OUTC - outflow of funds.

Net cash flow characterizes the stable financial state of small organizations, the prospects for increasing its value and attractiveness for investment. The definition of small organizations that have a positive cash flow can be performed using the logit regression model, a model used to determine the probability of occurrence of an event by the values of quantitative and qualitative variables.

Calculation of the coefficient of correlation of inflows and outflows of funds for 2010-2017 showed that there is a strong direct relationship between inflows and an outflow of cash, the correlation coefficient is 0.87 .

The analysis based on the binary logistic regression for the purpose of forecasting the company's cash flows can be carried out in the following sequence:

- conducting an assessment of the financial condition of the organization;

- determination of the sample of initial data for forecasting the cash flow;

- $\quad$ choice of the cash flow model;

- $\quad$ formation of a cash flow forecasting model;

- $\quad$ selection of critical parameters; selection of the distribution law for critical parameters;

- interpretation of the results of the statistical experiment.

1. Analysis of the financial condition of small business organizations is based on SPARK data, 60 companies with unstable financial condition are allocated.

2. Choice of the cash flow model. For our study, the dependent variable - net cash flow can take only two values - positive or negative, which corresponds to the dependent variable from the set of zeros and ones. It is necessary to assess the likelihood of a positive outcome depending on financial costs. The probability of more than one cannot be at any cost. In this case, the linear model cannot be used. Such requirements are satisfied by the logit model.

3. The formation of the cash flow forecasting model includes the following:

- $\quad$ introduction of the dependent variable (net cash flow) and independent variables (solvency of the organization, the ratio of borrowed funds and own funds, turnover of receivables, turnover of accounts payable, financial stability, tax burden, level of state support to small organizations);

- $\quad$ the construction of the variable $Z$, as a linear combination of the proposed independent variables;

- construction of the equation for the required probability of the event and finding the derivatives;

- realization of calculations by means of the program (maximum likelihood method is used);

- interpretation of the results of calculations.

The binary logistic regression model is expressed by the equation:

$$
p_{i}=F(Z i)=\frac{1}{1+e^{-2 i}}
$$

where $p_{i}$ - is the probability of the event being studied;

$z_{i}$ - is a linear combination of independent factors;

$\mathrm{e}-$ is the base of the natural logarithm 
$z=\beta_{0}+\beta_{1} x_{1}+\beta_{2} x_{2}+\ldots . \beta_{n} x_{n}$

Where $\beta_{0}$ - it acts as a "point of intersection",

$\beta_{1,} \beta_{2}, \beta_{n}$ - regression coefficients for independent variables.

The intersection point is the background value of the dependent variable, i.e. reflects the value of the value of $Z$, with the values of the argument-factors equal to zero. The regression coefficients reflect the level of influence of the corresponding argument-factor.

A positive sign before the regression coefficient indicates that this independent variable increases the probability of the event being investigated. A negative value of the coefficient means that this factor reduces the probability of the event being investigated. A large value of the regression coefficient means that this factor has a significant effect on the probability, an almost zero regression coefficient means that this factor has little effect on the dependent variable.

The limiting effect of the value of $Z$ on the probability is the derivative of the probability function:

$f(z)=\frac{d p}{d z}=\frac{e^{-z}}{\left(1+e^{-z}\right)^{2}}$

Z- is a function of the variable that determines the required probability, and $f(Z)$ - is the distribution density function (Figure 2).

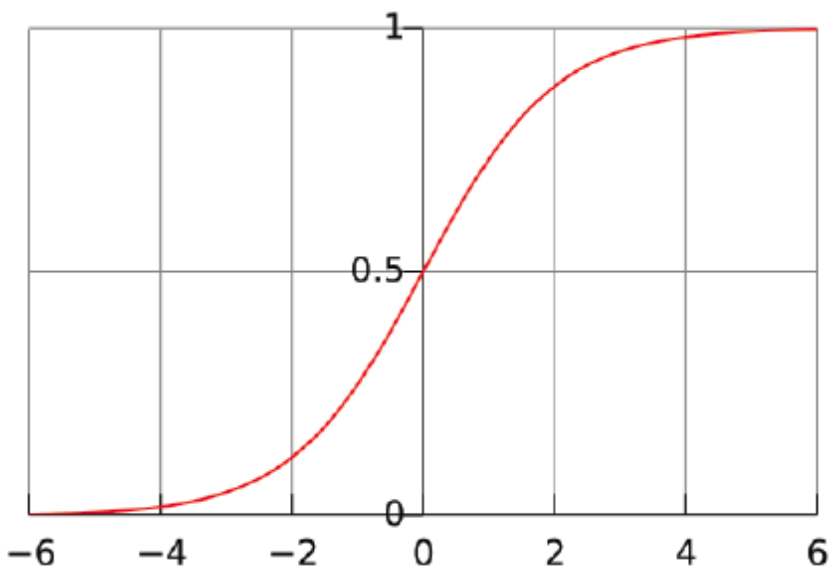

Figure 2: Logistic function, Z - abscissa axis, F ( $\mathrm{z}$ ) - ordinate axis.

The values of the logistic function can range from minus infinity to plus infinity, the function $F(z)$ can vary from 0 to 1 . The variable $Z$ reflects the susceptibility to some set of argument factors, the function $F(z)$ stands as the probability of a particular outcome, given the set factors.
For the considered set of small business organizations:

$$
\begin{aligned}
& Z=\beta_{1}+\beta_{2} C R+\beta_{3} F L+\beta_{4} R T R+ \\
& \beta_{5} E T A R+\beta_{6} P T R+\beta_{7} T+\beta_{8} R S S
\end{aligned}
$$

Z-dependent variable: 1 - if positive net cash flow, 0 - if negative net cash flow

CR - solvency of the organization;

FL - the ratio of borrowed funds and own funds;

ETAR - financial stability;

RTR - turnover of accounts receivable;

PTR - turnover of accounts payable;

$\mathrm{T}$ - tax burden;

RSS - the level of state support for small organizations.

You can calculate the logistic regression model in almost all programs for professional statistical data analysis such as SPSS, SAS, R, Statistic and others.

In the logit model, the coefficients have a multiplicative effect on the dependent variable, in contrast to the linear regression model. In this model, the parameters reflect the change in the probability of the value of $Y$, due to the change in $X$ by one unit, while the remaining parameters are taken as constants. The vector of the dependence is determined from the sign of the coefficient.

The model of logistic regression so formed allows predicting the dynamics of the financial state of a small organization that corresponds to the specific values of the initial indicators. A logistical model of the system dynamics of the net cash flow is constructed. The resulting indicator of the model - the forecast of the company's performance - is a kind of net cash flow. The offered logistical model allows investigating the dynamics of cash flows of a small organization, to forecast changes in financial results. Using the model, it is possible to forecast and neutralize the company's default. The model allows justifying developing the tactics and strategy of a small organization for protection against insolvency.

\section{RESULTS AND DISCUSSION}

The research has shown that for most small business organizations the issues of improving their 
financial condition and ensuring financial stability are priority. A significant number of small organizations in most cases have a lack of money and difficulties in attracting borrowed capital, therefore, the problems of rational cash management are important in ensuring solvency and financial sustainability.

The management of financing allows to take into account the multifactority and alternativeness of financial management in order to achieve the goals and objectives. In the absence of a purposeful approach, the activities of business entities become unreasonable and chaotic. As a result, the business entity is in great dependence on random situations. Therefore, the management of financing is an indispensable element of management, characterizes the ability to systematically identify deviations and, on this basis, make appropriate decisions. Ignoring the sound management of financing leads to a loss of the presentation of financial management objectives, to inadequate choice of forms, methods, means and mechanisms of financial management. Such processes are accompanied by a loss of dynamism and, at the same time, stability in the work of small organizations.

Modeling with the help of situational analysis makes it possible to develop alternative solutions for financing and, accordingly, improving the performance of small business organizations. With the help of modeling is carried out:

- analysis of ways and cycles, which makes it possible to analyze the cause-effect relationships between the factors affecting the effectiveness of financing small organizations;

- $\quad$ analysis of the conditions for the sustainability of the functioning of small organizations;

- $\quad$ identification of possible changes in the financing of small organizations.

The developed approach differs from existing methods: first, by the alternative, since the analysis of the model makes it possible to influence the most acceptable factors under the prevailing conditions; second, the objectively conditioned nature of the factors. This situation is explained by the fact that unlike most other methods, models are based on regularities, revealed on the basis of real financial indicators of the organizations in question. Within the framework of the new management paradigm, an approach to the management of financial resources with an orientation toward established goals is necessary, that is, the choice of a specific model for use in practice.

The study of such dependencies is of great importance for assessing the influence of various factors on the performance indicators of the business entity. According to this model, the level of profitability of capital determines the alternative of finding the directions of its increase. Each of the initial indicators is decomposed into a factor system with varying degrees of detail, which determines the boundaries for identifying and assessing financial reserves.

The analysis of the obtained modeling results allowed to give a qualitative characteristic of the obtained results:

- economic entities that show high and moderate profitability indicators prefer internal sources of financing economic activities to external sources. An increase in profitability also leads to a reduction in the use of debt financing resources;

- the tendency to increase the share of both longterm and short-term liabilities is weakly correlated with potential tax preferences. At the same time, for a number of economic entities, the increase in long-term sources of financing has a clear relationship with the prospect of using the "tax shield" effect;

- $\quad$ there is a direct relationship between the level of the debt burden and the variable that characterizes the growth rate of the organization. The growth rate is higher with lower debt load indicators;

- $\quad$ in general, the formation of the capital structure and the choice of sources of its financing are significantly influenced by traditional determinants, such as: profitability, financial risk, taxation, as well as growth rates, size and structure of assets;

the resulting set of determinants affecting the current structure of capital financing is different.

When making a decision on borrowing, small businesses should take into account financial stability indicators; return on equity; potential for attracting investments.

\section{CONCLUSION}

The identification of problematic factors on the basis of modeling allows us to conclude that limited access to 
financial resources reduces the motivation to increase the market value of the business. The current state contradicts the goal of managing the capital structure maximizing the company's market value based on optimizing the risk-return ratio of borrowing. The policy of using different sources of funding should be an adequate response policy - reducing the cost of raising funds.

The lack of own financial resources of small business organizations makes it necessary to attract borrowed funds. The accumulation of debt in relation to assets or revenues, that is, the growth of financial leverage, can positively affect the efficiency of the business functioning to a certain level. Rational capital structure assumes such a ratio between own and borrowed capital, which provides an optimal combination of risk and return and, therefore, maximizes the cost of business.

The proposed approach allows investigating the dynamics of financing sources for small organizations, to forecast changes in financial results. Modeling the model makes it possible to justify the tactics and strategy of small organizations to ensure financial sustainability.

The study of procedural limitations and application of the mathematical apparatus made it possible to conclude that the methods of system analysis can be used to identify stochastic dependencies in the examination of models of economic systems for managing financial resources of small business subjects.

\section{APPENDIX}

\section{Appendix 1: Table of Statistical Data [32]}

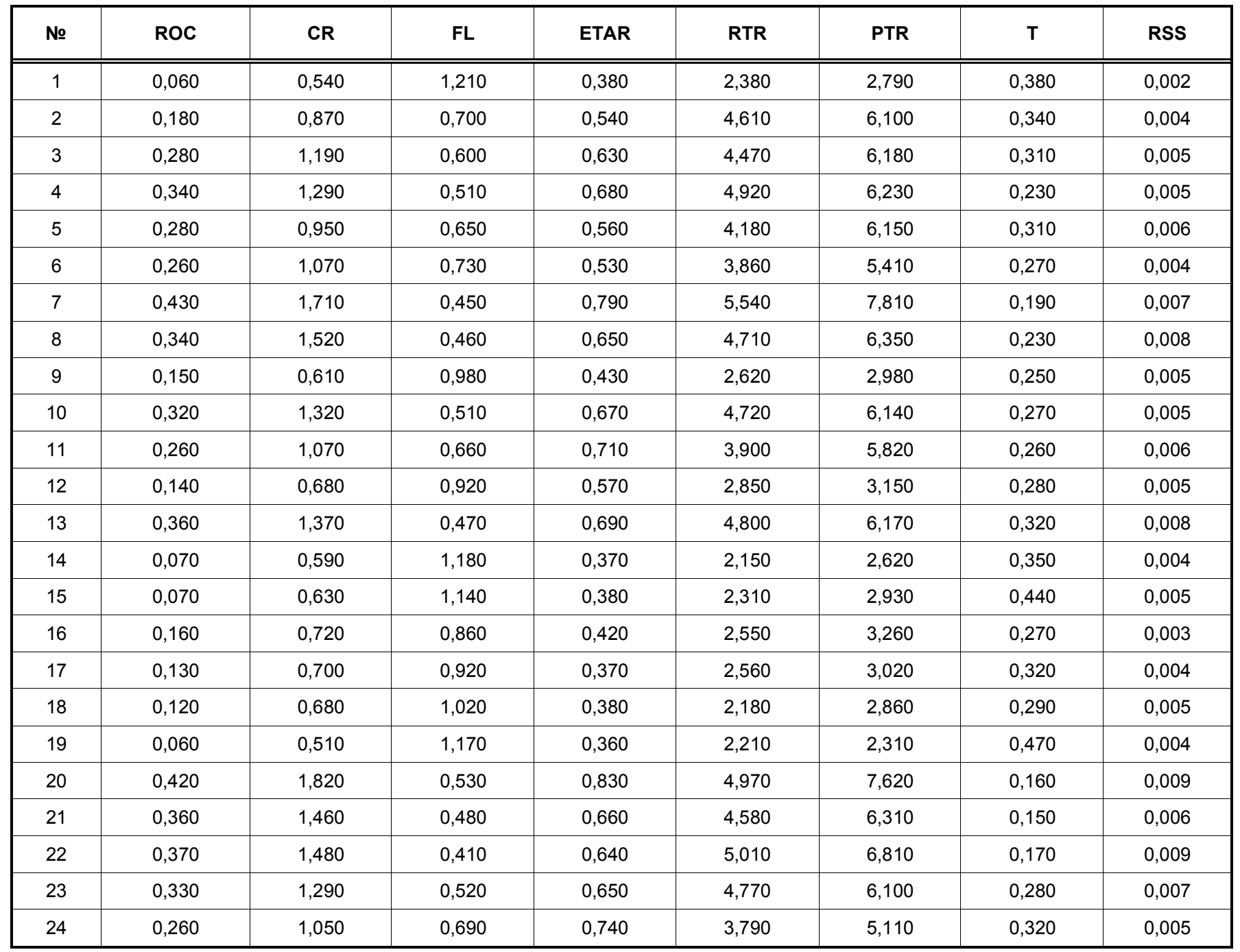




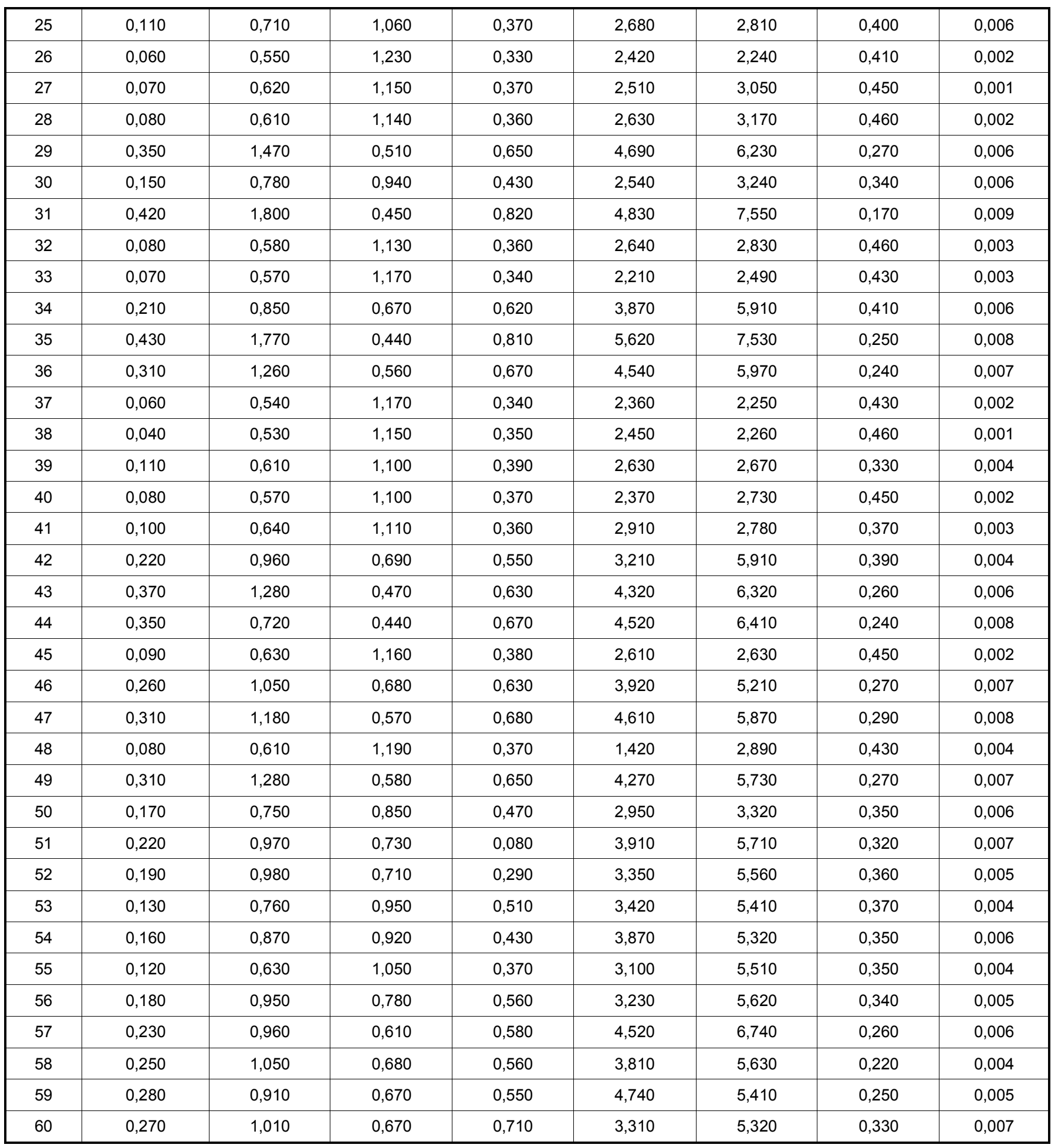

\section{REFERENCES}

Amel D., Mach T., (2017) The Impact of the Small Business Lending Fund on Community Bank Lending to Small Businesses. The Industrial Organization of Bank Lending 1. Volume 46, Issue 2: 307-328.

Bellucci A., Borisov A., Zazzaro A., (2017) Bank Organization and Loan Contracting in Small Business Financing. The World Scientific Reference on Entrepreneurship: 171-199.
Block J. H. , Colombo M.G. , Cumming D. J. , Vismara S.(2018) New players in entrepreneurial finance and why they are there. Small Business Economics, Vol. 50, Issue 2: 239-250.

Brealey R., Mayer's. (2012). Principles of Corporate Finance. - 2nd ed. - Moscow: ZAO Olympus-Business: 1120.

Copeland T., Koller T., Murrin J. (2008).Valuation Measuring and managing the value of companies. M.: Olimp-Business: 576 .

Damodaran A. (2008). Investment valuation. Tools and techniques for valuing any assets. Moscow. Alpina Business Books: 1342. 
Ding S., Jia C., Wu Z., Yuan W. (2017) Limited attention by lenders and small business debt financing: Advertising as attention grabber. International Review of Financial Analysis, Vol. 49: 69-82. https://doi.org/10.1016/.irfa.2016.12.003

Drover W., Busenitz L., Matusik S., Townsend D., Anglin A., Dushnitsky G. (2017) A Review and Road Map of Entrepreneurial. Equity Financing Research: Venture Capital, Corporate Venture Capital, Angel Investment, Crowdfunding, and Accelerators. Journal of Management. Vol. 43, No. 6: $1820-1853$.

Ferrando A. , Mavrakis E., Ferrando A. (2016). Non-Bank Financing for Euro Area Companies during the Crisis. Access to Bank Credit and SME Financing: 3-28.

Georgopoulos, V., Malandraki, G., \& Stylios, C. (2002). A fuzzy cognitive map approach to differential diagnosis of specific language impairment. Journal of Artificial Intelligence in Medicine, 679, 1-18.

Ghoshal D.M. (2005). Bad management theories are destroying good management practices. Academy of Learning \& Education, Vol. 4 No. 1:75-91.

Glykas, Michael (2010). Fuzzy cognitive maps: Advances in theory, methodologies.

Gurrea-Martínez A. (2016). The Low Use of Bankruptcy Procedures in Spain: Reasons and Implications for the Spanish Economy. Ibero-American Institute for Law and Finance, Working Paper Series No 5: 79.

Han L., Zhang S., Greene F.J. (2017) Bank market concentration, relationship banking, and small business liquidity. International Small Business Journal: Researching Entrepreneurship Vol 35, Issue 4: 1-35.

Higgins Robert C. (2007). Financial analysis: tools for making business decisions. M.: ID Williams: 464

Jensen M.C. (2002). Value maximization, stakeholder theory, and the corporate objective function. Business Ethics Quarterly, Vol 12: $235-247$.

Kaplan, R. S., \& Norton, D. P. (1996). Using the balanced scorecard as a strategic management system. In Harvard Business Review, January/February: 75-85.

Kosko B. (1986). Fuzzy cognitive maps. International Journal of ManMachine Studies. . vol. 1: 65-75.

Lambert T., Ralcheva A., Roosenboom P. (2018). The CrowdEntrepreneur Relationship in Start-Up Financing. The Economics of Crowdfunding: 57-78. https://doi.org/10.1007/978-3-319-66119-3 4

Lee, K. C., \& Kwon, O. B. (1998). A strategic planning simulation based on cognitive map knowledge and differential game. Journal of Simulation, 7(5): 316-327.

Lindgren M., Bandhold H. (2009). Scenario Planning: The Link between Future and Strategy. Palgrave Macmillan: 216.

Manan S. K, Abdullah M. A. (2012) Perception of Small- and Medium-Sized Enterprises towards Profit \& Loss Sharing Mode of Financing. Malaysian Journal of Economic Studies 49 (1): $37-48$.

Martínez-Sola C., García-Teruel P., Martínez-Solano P. (2018) Cash holdings in SMEs: speed of adjustment, growth and financing. Small Business Economics, Vol. 51, Issue 1: 1-20.

Miller S. M., Hoffer A., and Wille D., (2016) Small-Business Financing after the Financial Crisis: Lessons from the Literature.
Mercatus Working Paper, Mercatus Center at George Mason University, Washington, Arlington, VA, August 2016: 1-49.

Modigliani F. (1958). The Cost of Capital, Corporation Finance and the Theory of Investment. American Economic Review. №48: 261-297.

Myers S., Majluf N. (1984). Corporate financing and investment decisions when firms have information those investors do not have. Journal of Financial Economics. Vol .13, №2: 187221.

Osiyevsky O. Costa S. and Madill C.. (2016). Business Sense or Subjective Satisfaction? Exploring the Outcomes of Business Planning Comprehensiveness in Small and Medium Business Context. The International Journal of Entrepreneurship and Innovation, Volume 17, Issue 1: 15-30. https://doi.org/10.5367/ijei.2016.0207

Osterwalder A., Pine Y. (2012). Construction of business models: handbook of strategist and innovator. M. : Alpina Publisher. 288.

Othman, R. (2007). Enhancing the effectiveness of the balanced scorecard with scenario planning. International Journal of Productivity and Performance Management, 57: 259-266.

Pisani M. J., Guzman J.M., Richardson C., Sepulveda C., Laulié L.(2017) Small business enterprises and Latino entrepreneurship: An enclave or mainstream activity in South Texas? Journal of International Entrepreneurship. Volume 15, Issue 3: 295-323.

Rahman K.A. (2010). Development of Small and Medium Scale Enterprise in Bangladesh: Prospects and Constraints. Bangladesh Institute of Bank Management: 23.

Ross S. A. (1977). The determination of financial structure: the incentive-signaling approach. The Bell Journal of Economics. Vol. 8. № 1: 23-41.

Russian Statistical Yearbook. (2017): Stat.sb. Rosstat. M.: 728.

Saleem M. A., Khan D.I.( 2012) The impact of socio-economic factors on small business success. Malaysia Journal of Society and Space 8 issue 1:24 - 29.

St-Pierre J., Sakka O., Bahri M. (2018). External Financing, Export Intensity and Inter-Organizational Collaborations: Evidence from Canadian SMEs. Small Business Economics, Vol. 56,_Is 1: 68-87. https://doi.org/10.1111/jsbm.12390

Tools and applications. Studies in Fuzziness and Soft Computing Vol.247: 23.

Turner S., Endres Al., (2017). Strategies for Enhancing SmallBusiness Owners' Success. International Journal of Applied Management and Technology. Volume 16, Issue 1: 34-49.

Vries G.D., Pennings E, Block J.H. \& Fisch C. (2017) Trademark or patent? The effects of market concentration, customer type and venture capital financing on start-ups' initial IP applications. Journal Industry and Innovation. Volume 24, Issue 4:325-345

Wallmeroth J., Wirtz P., Groh A. (2018). Venture Capital, Angel Financing, and Crowdfunding of Entrepreneurial Ventures: A Literature Review, Foundations and Trends ${ }^{\circledR}$ in Entrepreneurship: Vol. 14: No. 1: 1-129.

Yihäinen I. Life-cycle effects in small business finance (2017) Journal of Banking \& Finance. Volume 77: 176-196.

\section{DOI: https://doi.org/10.6000/1929-7092.2018.07.74}

(c) 2018 Morozko et al.; Licensee Lifescience Global.

This is an open access article licensed under the terms of the Creative Commons Attribution Non-Commercial License (http://creativecommons.org/licenses/by-nc/3.0/) which permits unrestricted, non-commercial use, distribution and reproduction in any medium, provided the work is properly cited. 